\title{
Educación para la Ciudadanía Mundial: Una Innovación Curricular en Ciencias Sociales
}

\section{Global Citizenship Education: A Curricular Innovation in Social Sciences}

\author{
Nicolás Aguilar-Forero * \\ Diego Fernando Mendoza Torres \\ Ana María Velásquez \\ Daniel Felipe Espitia \\ Jennifer Ducón Pardey \\ Jana De Poorter \\ * Universidad de los Andes, Colombia
}

\begin{abstract}
Este estudio explora una innovación curricular en la clase de ciencias sociales de una escuela pública en Bogotá, Colombia, orientada a integrar algunos de los objetivos de la Educación para la Ciudadanía Mundial en los planes de estudio de los estudiantes de décimo grado. A través de un proyecto de investigación-acción se reformuló el plan de estudios del docente para enriquecerlo con una visión global de los temas tratados. Los resultados muestran cómo a través de estrategias lúdicas e innovadoras los estudiantes comprenden las diferencias entre distintos sistemas de gobierno y el sentido de la participación democrática. Asimismo, por medio de ejercicios comparativos, logran comprender la complejidad del conflicto armado en Colombia, en diálogo con los procesos de transición democrática acontecidos en otros países. Por último, gracias a ejercicios de investigación sobre movimientos sociales globales y al uso de portafolios, analizan las motivaciones y formas de acción de estos movimientos y se identifican empáticamente con la defensa de los derechos humanos. Con esta base, en este artículo se destacan lecciones aprendidas que pueden aportar a los maestros interesados en realizar innovaciones similares en sus aulas.
\end{abstract}

Descriptores: Educación; Ciudadanía; Ciencias sociales; Investigación-acción; Innovaciones educativas.

This study explores a curricular innovation in the social studies class of a public school in Bogota, Colombia, in order to integrate some of the Global Citizenship Education objectives in the curricula of tenth grade students. Through an action research project, we were able to reform the teacher's former plan of studies to enrich it with a global vision of the topics discussed. Results show how, through ludic and innovative strategies, students understand the differences among various government systems, and the sense of democratic participation. Likewise, through comparative exercises, they get to understand the complexity of armed conflict in Colombia, in dialogue with the processes of democratic transition that took place in other countries. Lastly, thanks to research activities about global social movements and to the use of portfolios, students analyze the motives and forms of action of those movements, and empathically identify themselves with the defense of human rights. Learned lessons for teachers interested in conducting similar innovations in their classrooms are highlighted.

Keywords: Education; Citizenship; Social sciences; Action research; Educational innovations.

*Contacto: nj.aguilar1902@uniandes.edu.co

Recibido:

1 de septiembre 2019

ISSN: 2254-3139

$1^{a}$ Evaluación: 27 de octubre 2019

www rinace.net/riejs/

$2^{\text {a }}$ Evaluación: 2 de diciembre 2019

revistas.uam.es/riejs

Aceptado: $\quad 8$ de diciembre 2019 


\section{Revisión de la literatura}

En 2015, la Organización de las Naciones Unidas (ONU) presentó la agenda mundial de desarrollo, dentro de la cual se incluyen 17 objetivos de desarrollo sostenible (ODS). Como parte del cuarto objetivo, orientado a proveer una educación de calidad, se propone:

... asegurar que todos los alumnos adquieran los conocimientos teóricos y prácticos
necesarios para promover el desarrollo sostenible, entre otras cosas mediante la
educación para el desarrollo sostenible y los estilos de vida sostenibles, los derechos
humanos, la igualdad de género, la promoción de una cultura de paz y no violencia,
la ciudadanía mundial y la valoración de la diversidad cultural y la contribución de
la cultura al desarrollo sostenible. (ONU, s.f., meta 4.7)

De esta manera, la Educación para la Ciudadanía Mundial (ECM) emerge como una de las estrategias que pueden contribuir a alcanzar los ODS y, en particular, el objetivo cuatro relativo a la calidad de la educación. Para la UNESCO (2015), la ECM "refiere a un sentido de pertenencia a una comunidad más amplia y a una humanidad común. Hace hincapié en la interdependencia política, económica, social y cultural y en las interconexiones entre los niveles local, nacional y mundial" (p. 14). A pesar de ser un concepto y estrategia emergente, la UNESCO (2018) ha resaltado experiencias en diferentes países en los que, desde distintos enfoques y conceptos educativos locales, se ha aportado a hacer realidad los tres principios centrales de la ECM que la distinguen de otras estrategias educativas: "respeto por la diversidad, solidaridad y sentido compartido de humanidad" (p. 4). El caso de Colombia es un buen ejemplo de cómo, desde un programa local como el de Competencias Ciudadanas del Ministerio de Educación Nacional (MEN), ya se tiene una base para alcanzar los objetivos y principios de la ECM, a partir de los Estándares de Competencias Ciudadanas (2004). Estos estándares se organizan en tres grandes categorías que representan dimensiones centrales del ejercicio ciudadano: convivencia y paz, participación y responsabilidad democrática, y pluralidad, identidad y valoración de las diferencias (MEN, 2004; Jaramillo y Mesa, 2009).

El avance desarrollado en Colombia en esta materia llevó a que el país fuera incluido en 2016 en un proyecto de desarrollo curricular liderado por el Centro de Asia y el Pacífico de Educación para el Entendimiento Internacional (APCEIU, por su sigla en inglés), una agencia de segundo nivel de la UNESCO. En dicho proyecto se invitó a cuatro países a embarcarse en la meta de integrar los objetivos de ECM en sus currículos nacionales. Fruto de este proyecto, el MEN construyó unos Lineamientos de Formación de Educadores para la Ciudadanía (MEN, 2018), con los cuales se pretende ofrecer orientaciones a las Facultades de Educación en Colombia sobre cómo formar en los conocimientos y las competencias que los estudiantes de pregrado y posgrado en educación requieren para promover la educación para la ciudadanía y la ECM en sus prácticas pedagógicas. Sin embargo, si bien los lineamientos propuestos por el MEN son una iniciativa importante para promover la ECM en el país, requieren ser complementados con ideas concretas en torno a la manera como los docentes pueden implementar la ECM en su práctica.

Cabe destacar que el concepto de ECM ha sido ampliamente discutido en la literatura académica (Andreotti, 2011; Andreotti y Pashby, 2013; Boni, Hofmann-Pinilla y Sow, 2012; Pais y Costa, 2017; Parmenter, 2011; Peraza, 2016; Truong-White y Mclean, 2015; Arthur, 2014; Balarin, 2011; Jooste y Heleta, 2017; Nieto, 2017; Standish, 2014). Entre algunos de los enfoques que proponen una perspectiva al respecto, están el neoliberal, el anti-ciudadanía mundial, el decolonial y el crítico/transformador. El enfoque neoliberal propone que la ECM debe preparar a los estudiantes para adecuarse y aportar a la 
productividad en una economía global. El enfoque anti-ciudadanía mundial invita a abandonar el concepto en sí mismo en tanto se considera en exceso abstracto o contradictorio con la idea de que la ciudadanía requiere pertenecer a una nación. El enfoque decolonial invita a problematizar el concepto en tanto puede estar favoreciendo una perspectiva de ciudadano principalmente eurocentrista, y a enfatizar en las particularidades socioculturales de cada contexto. Finalmente, el crítico/transformador pone el énfasis en la comprensión de las relaciones de poder y en la participación de los individuos para transformar las comunidades en búsqueda de la justicia social (ver una discusión más detallada sobre estos enfoques en Aguilar-Forero y Velásquez, 2018; Aktas et al., 2017; Hartung, 2017; Cho y Mosselson, 2017; Veugelers, 2011; Shultz, 2007).

La UNESCO, en este marco, al ser parte de la ONU y actualmente una de las principales promotoras de la ECM, se esfuerza por comprometer a las personas y naciones con el desarrollo sostenible, el respeto de las diferencias, la inclusión y la formación de una ciudadanía que pueda construir un mundo cada vez mejor al que tenemos en la actualidad (Han, 2016). Ello dialoga con la concepción de formación ciudadana propuesta en los Estándares Básicos de Competencias Ciudadanas del MEN, a los que ya se hizo referencia. Desde estos estándares se busca:

\begin{abstract}
Apoyar el desarrollo de las competencias y los conocimientos que necesitan niños, niñas y jóvenes del país para ejercer su derecho a actuar como agentes activos y de manera constructiva en la sociedad: para participar activa y responsablemente en las decisiones colectivas de manera democrática, para resolver los conflictos en forma pacífica y para respetar la diversidad humana, entre otros [elementos] importantes, como proteger el medio ambiente. En otras palabras, formar de manera reflexiva y deliberada para proteger y promover los Derechos Humanos y hacer realidad la sociedad que soñamos. (MEN, 2006, p. 154)
\end{abstract}

En ese sentido, se puede afirmar que tanto las propuestas de la UNESCO como las del MEN dialogan con el enfoque crítico/transformador, en la medida en que buscan formar ciudadanos que respetan y valoren las diferencias, promuevan los Derechos Humanos y participen activa y democráticamente en la construcción de un mundo mejor, más justo, inclusivo y sostenible. Este es el mismo enfoque desde el cual se enmarca la presente investigación. Desde este enfoque el profesor se constituye en un agente esencial para la formación ciudadana de los niños, las niñas y los jóvenes, como se estipula y promueve en la Ley General de Educación (1994) en la que se otorga un rol central al docente, al conceder autonomía a las instituciones educativas para:

\begin{abstract}
organizar las áreas fundamentales de conocimientos definidas para cada nivel, introducir asignaturas optativas dentro de las áreas establecidas en la ley, adaptar algunas áreas a las necesidades y características regionales, adoptar métodos de enseñanza y organizar actividades formativas, culturales y deportivas, dentro de los lineamientos que establezca el Ministerio de Educación Nacional. (p. 17)
\end{abstract}

Esto implica que, si bien los Estándares y lineamientos del MEN son un referente de las metas mínimas que se deben alcanzar en la educación para todos los estudiantes de Colombia, las metas específicas más allá de estos mínimos y las estrategias para llegar a ellas, deben ser construidas por la comunidad educativa a nivel local. Esto empodera al profesor como agente de su currículo, quien es llamado a indagar, explorar y proponer las mejores maneras de integrar y adaptar los objetivos de educación para la ciudadanía y de ECM en su currículo. Es por esto que esta investigación se sitúa en la práctica particular de un profesor de ciencias sociales, quien, en colaboración con un equipo de investigación, se propuso diseñar, implementar y evaluar estrategias de integración de objetivos de ECM 
en sus clases, dirigidas a estudiantes de grado décimo de un colegio oficial de Bogotá. Dicho proceso y sus resultados se exponen en el presente artículo.

Es importante mencionar que, desde el Proyecto Educativo Institucional y el plan de área de ciencias sociales de la institución educativa en la que se realizó el estudio, se promueve que los estudiantes que cursan la educación media analicen su entorno social y político, a la luz de los problemas globales, tanto históricos como presentes. En particular, como eje integrador del área de ciencias sociales para grado décimo, se propone que los estudiantes observen "los factores que ayudan al desarrollo espacial, histórico, político, económico, social y cultural de Colombia y Latinoamérica en proporción con otros territorios del planeta" (Plan de área, 2015, p. 50). En este marco, se encuentra una oportunidad para diseñar, implementar y analizar tres procesos políticos a la luz de la ECM: los sistemas de poder y de participación en la historia y en el país; el conflicto armado, sus orígenes, trayectorias y dinámicas de reconstrucción de paz en Colombia y en el mundo; y los movimientos sociales como instancias de manifestación y resistencia frente a las injusticias sociales. Estos procesos se encuentran alineados con los temas y objetivos de ECM propuestos para este rango etario (jóvenes entre 14 y 17 años) por la UNESCO (2015).

En síntesis, este estudio busca aprovechar la coyuntura de apoyo desde la ONU y la UNESCO a la educación para la ciudadanía y la ECM, con el propósito de diseñar, implementar y evaluar una iniciativa de innovación curricular en la clase de ciencias sociales de un profesor de grado décimo de un colegio público localizado en la capital colombiana. En particular, se proponen tres experiencias pedagógicas para trabajar los tres procesos mencionados, entablando diálogos entre el contexto colombiano y problemáticas mundiales del pasado o de la actualidad. La investigación y el presente artículo dan cuenta de una evaluación formativa de las tres experiencias, a partir de la sistematización de las actividades por parte del profesor, de las reflexiones del grupo de investigación y del análisis de los productos realizados por los estudiantes durante las clases. Todo lo anterior con el fin de responder a la siguiente pregunta de investigación: ¿Cuál es el potencial de las tres experiencias pedagógicas propuestas para promover la ECM? La pregunta se acompaña de dos objetivos fundamentales de investigación: analizar las competencias de ciudadanía mundial que se desarrollaron en estudiantes de secundaria por medio de las tres experiencias pedagógicas propuestas; e identificar, luego del diseño, implementación y evaluación de dichas experiencias, posibilidades y lecciones aprendidas que puedan ser replicadas en otros contextos.

\section{Método}

El enfoque metodológico en el que nos apoyamos a lo largo de esta experiencia fue la investigación-acción. Como señala Latorre (2007) la investigación-acción es una forma de indagación realizada por los docentes para mejorar sus prácticas con base en evidencias obtenidas de los datos y del juicio crítico de otras personas. Se trata de una aproximación en la que se une teoría y práctica, investigación y acción, saber y hacer, con el fin de alcanzar distintos fines prácticos: desarrollo curricular, autodesarrollo profesional, fortalecimiento de procesos o programas educativos, entre otros. Se caracteriza por el diseño e implementación de estrategias de acción que son sometidas a observación, reflexión y cambio. Por lo tanto, su propósito es la transformación educativa y social, a la cual se llega a través de la generación de conocimientos sobre las prácticas y realidades en las que se interviene. Para alcanzar este propósito se siguen ciertos ciclos que implican 
"un vaivén -espiral dialéctica- entre la acción y la reflexión, de manera que ambos momentos quedan integrados y se complementan” (p. 32). Para efectos de este estudio la investigación-acción se desarrolló a través del siguiente procedimiento metodológico:

\section{Diseño del plan de acción}

A mediados del año 2017 se conformó un equipo de investigación integrado por investigadores y practicantes de la Universidad de los Andes, y un docente de ciencias sociales de una institución del sector oficial. El propósito inicial fue conocer a fondo el currículo que el docente aplicó en el año lectivo 2017, con el fin de encontrar escenarios de posible intervención y transformación en los que se pudieran incluir estrategias de ECM. Para ello se realizaron reuniones durante casi cuatro meses, en las que se discutieron varios referentes teóricos y se procedió con el diseño de las distintas unidades. Estas unidades dan cuenta no solo de los diferentes objetivos construidos de manera integrada entre el área de ciencias sociales y los objetivos de ECM planteados por la UNESCO (2015), sino que también dan una primera idea del tipo de actividades y estrategias que permiten hacer realidad el proyecto de integración de la ECM en el aula. Para este caso se identificaron oportunidades para integrar actividades de ECM en tres unidades que ya se venían trabajando: democracia y participación, conflicto armado y movimientos sociales.

\section{Implementación de acciones}

Desde febrero hasta agosto de 2018 se implementaron las actividades previamente diseñadas. Entre estas actividades se adelantaron cine-foros, talleres, teatro-imagen, juegos de roles, salidas pedagógicas, entre otros, las cuales fueron dinamizadas directamente por el docente de la institución educativa y por una de las investigadoras de la Universidad. Las actividades se implementaron con un total de 93 estudiantes (43 hombres y 50 mujeres) con edades que oscilaban entre los 14 y los 17 años, pertenecientes a tres grupos de grado décimo de la jornada mañana de una institución educativa distrital de la localidad de Puente Aranda en Bogotá, Colombia. Los estudiantes participantes provienen de contextos propios de los niveles socioeconómicos medios y bajos, con familias integradas mayoritariamente por padres y madres trabajadores independientes, empleados como operarios en niveles técnicos y, en menor medida, profesionales.

Cada uno de los jóvenes recibió un consentimiento informado que fue leído y aprobado por sus padres y acudientes, y que evidenció el deseo de participar libremente en la investigación aportando información de manera anónima. En ningún momento la investigación representó un riesgo para los estudiantes, quienes, además, fueron tratados con los debidos protocolos en todas las fases del proceso. Entretanto, la institución representada en los directivos docentes, fue informada del propósito de la investigación y al contar con la participación directa de un docente de planta del área de ciencias sociales, facilitó su desarrollo y garantizó la retribución a la población en términos de cualificación de los programas académicos y dinamización de las experiencias de aprendizaje para los estudiantes. Finalmente, los resultados de la investigación han sido debidamente socializados con los estudiantes y se espera que en una jornada pedagógica se puedan presentar a los demás maestros del colegio.

\section{Observación y registro de actividades}

En paralelo a la fase anterior, se implementaron un conjunto de técnicas de investigación que permitieron evaluar los resultados de la intervención. La técnica principal fue la observación participante registrada en diarios de campo, la cual se acompañó de registros 
en video de las actividades más significativas que tuvieron lugar a lo largo del estudio. De igual forma, con el fin de registrar y evaluar los aprendizajes derivados de las distintas sesiones de la primera unidad (democracia y participación), se implementó la herramienta conocida como mapeo personal de significados (PMM por su sigla en inglés), instrumento diseñado para medir cómo una experiencia de aprendizaje afecta diferencialmente el entramado emocional, conceptual y comportamental de los sujetos, indagando no sólo por qué se aprende sino por cómo se aprende (Falk, 2003). Esta herramienta consta de tres momentos:

- Antes de iniciar las actividades de cada unidad se pide a los estudiantes que, de manera individual, hagan una lluvia de ideas (palabras, frases, conceptos) relacionadas con un concepto motivador como, en este caso, participación democrática.

- Después de haber terminado las cinco sesiones de la unidad, se pide a cada estudiante que intervenga de nuevo su mapa previo, subrayando las ideas que ya no considera pertinentes y agregando, con un color diferente al utilizado en su mapa previo, nuevas palabras, ideas o conceptos.

- Para terminar, al respaldo de su mapa o en una hoja aparte cada estudiante justifica por qué realizó ciertos cambios en su mapa, por ejemplo, por qué suprimió ciertas palabras y por qué asoció otras nuevas al concepto motivador.

Para evaluar los aprendizajes e interpretar los progresos a lo largo de la segunda unidad (conflicto armado), se diseñó una ficha donde los estudiantes organizaron sus ideas, conceptos, análisis y perspectivas a la luz de sus experiencias de aprendizaje durante las distintas sesiones. La ficha titulada para el estudio matriz de análisis de conflictos les permitió a los estudiantes comprender antecedentes, causas, hechos, consecuencias y soluciones de los conflictos estudiados (Colombia, El Salvador, Ruanda e Irlanda del Norte), así como establecer semejanzas y diferencias en las experiencias de cada país.

Finalmente, en cuanto a la unidad de movimientos sociales, la herramienta de evaluación empleada por el equipo de docentes-investigadores fue el portafolio. Cada uno de los tres grupos de grado décimo se dividió en tríadas de estudiantes que representaron un movimiento social con impacto a nivel global y, así, cada equipo de trabajo diseñó y habilitó una carpeta o portafolio donde almacenó las actividades desarrolladas por su grupo, así como las compartidas por los compañeros de otros movimientos sociales. Aquí recopilaron, entre otros, logos, canciones y fichas de películas trabajadas en las diferentes sesiones, alusivas a cada movimiento.

Reflexión y análisis de los resultados

Luego de diseñar e implementar un plan de acción y de observar las actividades con el fin de recolectar evidencias para evaluarlas, se reflexionó sobre las acciones registradas a través de discusiones entre los distintos miembros del grupo. El propósito de esta reflexión fue reconstruir el significado de la experiencia de investigación-acción e identificar claves que permitieran replicar las actividades realizadas en otros contextos similares. Es importante señalar que las fases acá descritas no fueron necesariamente secuenciales, pues por el contrario se sobrepusieron constantemente y se reforzaron entre sí. En el caso de la reflexión, a lo largo de todo el ciclo, el grupo de trabajo se reunió semanalmente para realizar ajustes al plan de acción, compartir impresiones sobre las actividades realizadas y hacer lecturas de contexto y de los grupos de estudiantes con los 
que se trabajó. Asimismo, en estas reuniones, que también fueron registradas en un formato previamente diseñado, fue posible evaluar acciones previas y coordinar la realización de acciones futuras.

Toda la información derivada de la implementación y observación de acciones fue analizada con base en los objetivos propuestos para cada unidad. Para el caso de la primera unidad, en la que se evaluaron los aprendizajes con base en el PPM, tuvimos en cuenta dos de las dimensiones analíticas propuestas por Falk (2003), las cuales arrojan resultados tanto cuantitativos como cualitativos:

- Amplitud (Breadth): mide la amplitud de conocimientos y aprendizajes generados a partir del conteo de la cantidad de conceptos apropiados. Para esto se determina el total de conceptos relevantes plasmados, es decir, se compara cuántos conceptos se utilizaron antes y después de la experiencia de formación.

- Profundidad (Depth): mide el grado de profundidad o riqueza que tienen los conceptos a partir del nivel de conexiones o grado de complejidad de los conceptos incluidos. Para esto se tienen en cuenta aspectos fundamentales como la cohesión (si los conceptos son interdependientes o se exponen de manera dispersa), la jerarquía (si el mapa organiza conceptos exponiendo algunos como más importantes, centrales o globales que otros) y la "vinculación emocional", esto es, las palabras, frases o expresiones que expresan inquietudes, necesidades o posiciones (neutrales, positivas o negativas) frente al concepto motivador.

Los resultados obtenidos en las distintas categorías se analizaron a la luz de los tres objetivos de esta unidad: 1) identificar y comprender la organización de diferentes sistemas de gobierno, a nivel local, nacional y mundial; 2) evaluar críticamente la democracia como sistema de organización social; 3) aportar a la construcción de su comunidad a través de la participación en asuntos de interés común.

Cuadro 1. Matriz utilizada para el análisis de las unidades 2 y 3

\begin{tabular}{|c|c|c|c|}
\hline UNIDADES & OBJ. COGNITIVO & OBJ. SOCIOEMOCIONAL & OBJ. CONDUCTUAL \\
\hline $\begin{array}{l}\text { Conflicto } \\
\text { armado }\end{array}$ & $\begin{array}{l}\text { ¿Los estudiantes } \\
\text { identifican las causas y } \\
\text { consecuencias políticas, } \\
\text { económicas, sociales y } \\
\text { ambientales de los } \\
\text { conflictos armados en el } \\
\text { contexto nacional y } \\
\text { mundial? }\end{array}$ & $\begin{array}{l}\text { ¿Logran cultivar la empatía } \\
\text { y la solidaridad hacia otros } \\
\text { individuos y grupos } \\
\text { sociales, para convivir } \\
\text { pacífica y } \\
\text { constructivamente en medio } \\
\text { de la diferencia y la } \\
\text { pluralidad? }\end{array}$ & $\begin{array}{l}\text { ¿Proponen acciones } \\
\text { para aportar a la } \\
\text { construcción de paz } \\
\text { de cara al } \\
\text { posconflicto en } \\
\text { Colombia? }\end{array}$ \\
\hline $\begin{array}{l}\text { Movimientos } \\
\text { sociales }\end{array}$ & $\begin{array}{l}\text { ¿Los estudiantes } \\
\text { examinan críticamente } \\
\text { los problemas locales, } \\
\text { nacionales y mundiales } \\
\text { frente a los cuales } \\
\text { reaccionan los } \\
\text { movimientos sociales, } \\
\text { así como sus formas de } \\
\text { acción colectiva? }\end{array}$ & $\begin{array}{l}\text { ¿Se identifican y } \\
\text { comprometen } \\
\text { empáticamente con la } \\
\text { reivindicación de grupos } \\
\text { marginados? }\end{array}$ & $\begin{array}{l}¿ \text { Defienden las } \\
\text { causas de los } \\
\text { movimientos } \\
\text { sociales y se } \\
\text { manifiestan pacífica } \\
\text { y creativamente } \\
\text { para divulgarlas? }\end{array}$ \\
\hline
\end{tabular}

Fuente: Elaboración propia.

En el caso del análisis de la segunda y la tercera unidad, se codificó la información recopilada (transcripciones de videos, matriz de análisis de conflictos y portafolios) teniendo en cuenta ciertas preguntas orientadoras relacionadas, igualmente, con los 
objetivos de cada una de estas unidades. Dichos objetivos se apoyaron en los tres ámbitos de aprendizaje propuestos por la UNESCO (2015) como transversales a las estrategias de ECM: el cognitivo, el socioemocional y el conductual. Esta información se organizó en una matriz que permitió establecer conexiones y comparaciones entre los datos obtenidos. La base de dicha matriz aparece en el cuadro 1.

\section{Resultados}

El proceso de planeación colectiva se materializó en un plan de acción flexible y adaptable a efectos imprevistos (Latorre, 2007), expresado en un diseño curricular en el que se plantearon objetivos, competencias, actividades y recursos para cada una de las tres unidades seleccionadas. A continuación, se describen las características y resultados de tales unidades y de algunas de sus actividades más significativas:

\subsection{Democracia y participación: Teatro-imagen sobre los sistemas de gobierno}

En la unidad de democracia y participación se realizó una actividad denominada teatroimagen que inicialmente no se encontraba dentro de la planeación; sin embargo, en una de las sesiones previas a la clase el equipo decidió incluirla puesto que permitía abordar la temática de los sistemas de gobierno mediante una apuesta innovadora. Como parte de la actividad se distribuyeron en los distintos cursos siete sistemas de gobierno (monarquía, democracia, teocracia, aristocracia, oligarquía, totalitarismo y anarquía) en grupos de entre cuatro y cinco estudiantes. Tales grupos, luego de trabajar una guía temática y de apropiarse de las principales características del sistema de gobierno que les correspondió, debieron escenificarlo en una fotografía en la que cada integrante tenía que desempeñar un rol específico. Más adelante, cada grupo presentó ante todos sus compañeros la imagen para que, a través de la interpretación de la gestualidad y el escenario marco de la fotografía, los compañeros identificaran el sistema de gobierno expuesto. En el cierre de la actividad se hizo una explicación y socialización desde el contenido de la guía y los análisis de cada grupo.
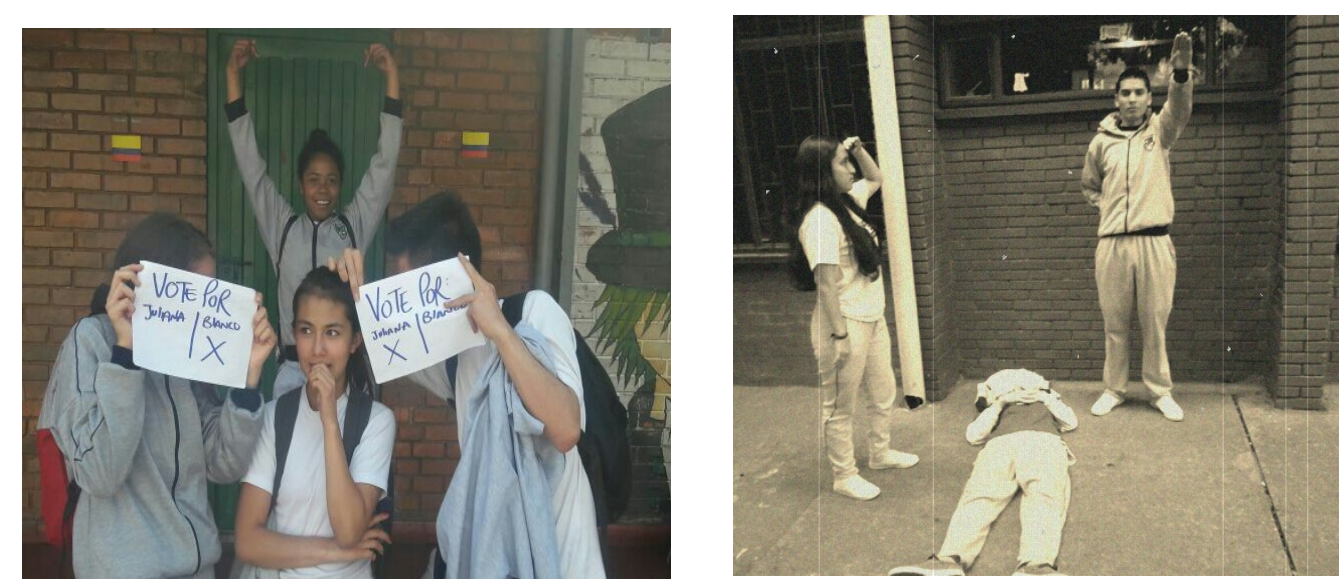

Figura 1. Teatro-imagen sobre democracia (izq.) y totalitarismo (der.)

Fuente: estudiantes de 1001 y 1002. Fotografías tomadas por autores.

Esta actividad de la unidad de democracia y participación evidenció varios aprendizajes que quedaron plasmados en el PPM. Por ejemplo, para el caso del grupo de 32 estudiantes del curso 1003, se identificó la emergencia de 105 conceptos nuevos que se sumaron a los 
296 conceptos que los estudiantes ya habían plasmado en sus mapas previos. De igual forma, al comparar los conceptos que los estudiantes asociaron mayoritariamente a la participación democrática antes y después de la actividad de teatro-imagen, se identificaron cuatro conceptos significativos que se repitieron más de 10 veces en los mapas previos del grupo. En los mapas posteriores estos conceptos se mantuvieron, es decir, los estudiantes no los eliminaron de su mapa, pero los complementaron con otros cuatro conceptos que encontraron relevantes (cuadro 2).

Cuadro 2. Comparación de mapas previos y posteriores del curso 1003

\begin{tabular}{lclc}
\hline \multicolumn{1}{c}{ MAPAS PREVIOS } & \multicolumn{2}{c}{ MAPAS POSTERIORES } \\
\hline \multicolumn{1}{c}{ Conceptos } & Recurrencia & \multicolumn{1}{c}{ Conceptos } & Recurrencia \\
\hline Democracia representativa & 73 & Pueblo & 18 \\
Democracia participativa & 59 & Liderazgo & 15 \\
Toma de decisiones & 14 & Poder & 12 \\
Derechos y deberes & 11 & Gobierno & 10 \\
\hline
\end{tabular}

Fuente: Elaboración propia.

Más allá del análisis cuantitativo que permite evidenciar amplitud conceptual, en la medida que los estudiantes agregaron a su mapa conceptos nuevos y relevantes como pueblo, liderazgo, poder y gobierno que se abordaron durante la clase, el análisis cualitativo permitió ver otros elementos. Por ejemplo, con respecto a la profundidad de los aprendizajes, los mapas posteriores evidencian que la actividad permitió modificar ciertos comentarios negativos frente a la participación democrática, presentes en los mapas previos. En efecto, antes de la actividad los estudiantes asociaron el concepto (participación democrática) a ideas como las siguientes: promesas falsas, elegir a los mismos, personas corruptas, personas que roban una nación, entre otras. Otros estudiantes, si bien no expresaron explícitamente ideas negativas, sí plantearon interrogantes que dan cuenta de cierta desconfianza frente a la participación democrática. Tal es el caso del siguiente mapa en donde se identifican las preguntas ¿honestidad? ¿politiquería?

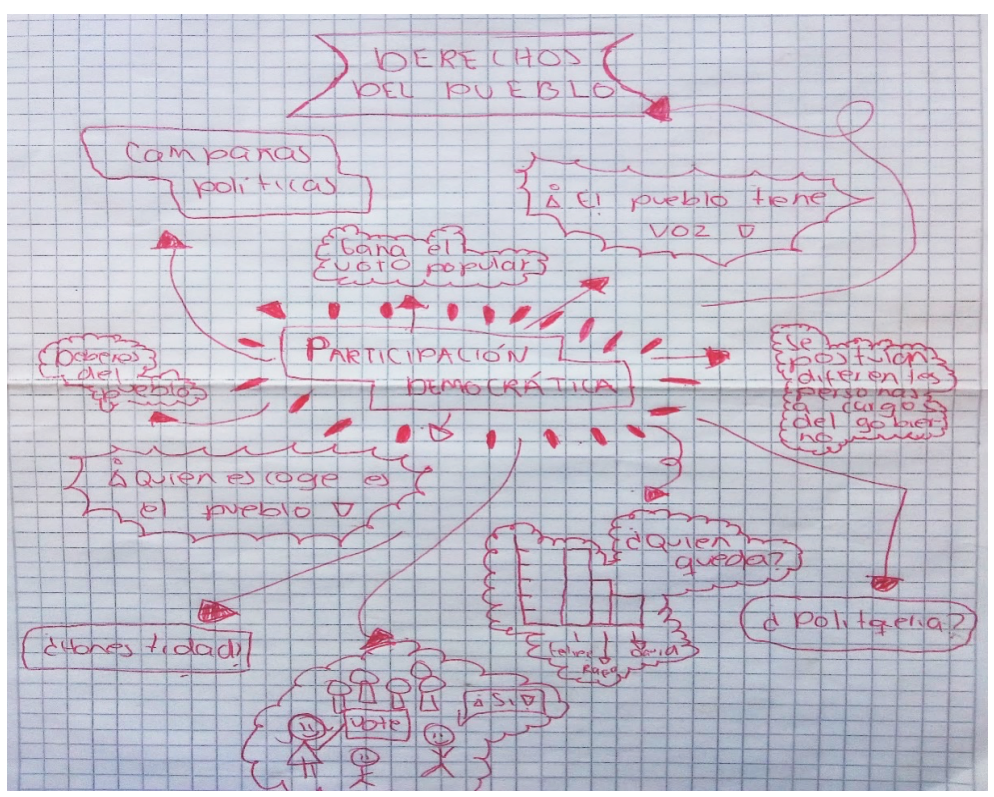

Figura 2. Mapa previo de estudiante de grado 1003

Fuente: Fotografía tomada por autores. 
Sin embargo, tales asociaciones negativas frente a la participación democrática disminuyeron en los mapas posteriores y, en algunos casos, algunas expresiones negativas se remplazaron por términos como libertad, respeto de las diferencias, unión, entre otros. En algunos casos más, predominó un vínculo emocional neutral frente al concepto, asociado a la comprensión o definición de los distintos sistemas de gobierno abordados. Sin embargo, entre los sistemas de gobierno se encuentra mayor recurrencia y profundidad en los aprendizajes en relación con democracia y monarquía, lo cual contrasta con las pocas alusiones al totalitarismo (solo se menciona dos veces en los mapas posteriores) y la ausencia de menciones a aristocracia. A pesar de ello en varios de los mapas posteriores se identifican comprensiones abarcadoras en las que se hace referencia a varios de los sistemas abordados:

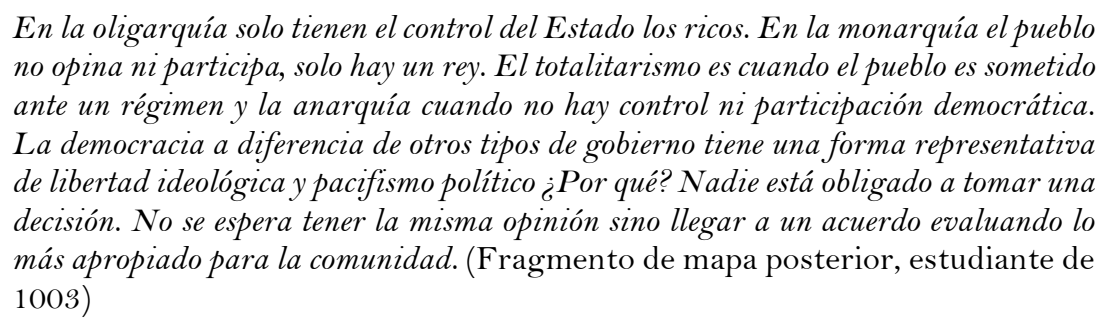

Para terminar, en lo que concierne a la estructura de los mapas, no se identificaron cambios en los mapas posteriores que evidenciaran mayor complejidad de los aprendizajes, como resultado del establecimiento de nuevas conexiones, interdependencias o jerarquías entre los conceptos agregados. Tampoco se evidenciaron conocimientos o comprensiones que den cuenta del interés de los estudiantes por aportar a la construcción de su comunidad por medio de su participación democrática, lo cual indica la necesidad de fortalecer el ámbito conductual de la ECM al implementar este tipo de estrategias pedagógicas (este aspecto se retoma más adelante, en la discusión y conclusiones). Pese a lo anterior, en los ámbitos cognitivo y socioemocional sí se evidenciaron aprendizajes significativos, en especial en la comprensión de los diferentes sistemas de gobierno con cierto énfasis en la democracia como forma de representación, liderazgo y participación social.

\subsection{Conflicto armado: Matriz comparativa de conflictos armados en el mundo}

A lo largo de esta unidad se buscó que los estudiantes identificaran las causas y consecuencias políticas, económicas, sociales y ambientales de los conflictos armados tanto a nivel nacional como mundial. Para ello, se abordó el caso colombiano y tres casos internacionales (Uganda, Irlanda del Norte y El Salvador) que permitieron ejemplificar y comparar la naturaleza de estos conflictos desde su origen hasta su desenlace. Lo anterior permitió que los estudiantes analizaran y comprendieran que un conflicto no se debe a un solo aspecto, sino a un cúmulo de factores tanto estructurales como coyunturales que, al juntarlos, permiten explicar íntegramente el porqué de cierto proceso o situación.

Para lograr dicho cometido, los estudiantes desarrollaron una actividad acompañada de presentaciones magistrales por parte del equipo docente. Esta consistió en llenar una tabla comparativa que contaba con cuatro filas en donde se encontraban los países, y cinco columnas para sintetizar elementos significativos en relación con antecedentes, causas, hechos, consecuencias y soluciones de cada conflicto. El objetivo de esta tabla era que los estudiantes lograran establecer un diálogo entre los diferentes casos y, así, comprender que los conflictos no necesariamente se pueden entender aisladamente sino también sistémicamente, es decir, teniendo en cuenta ciertos elementos estructurales que conectan 
las causas y consecuencias de distintos conflictos, como por ejemplo el problema de la tierra (figura 3).

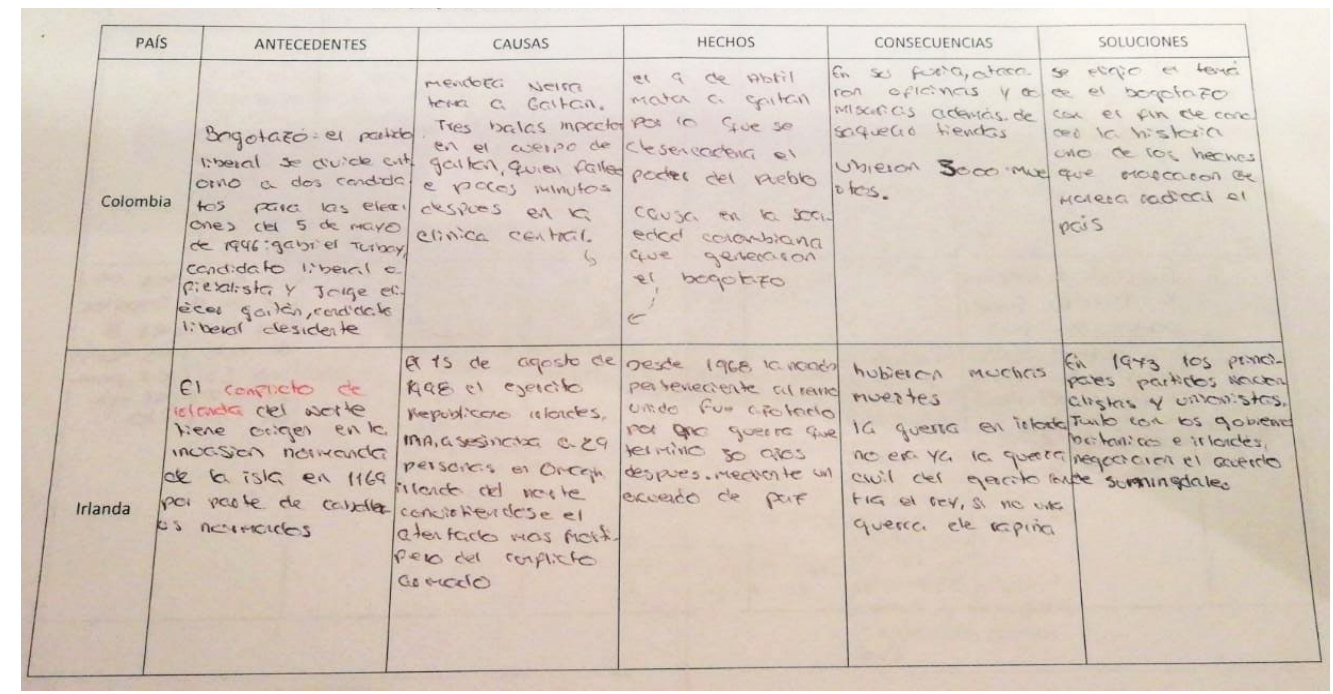

Figura 3. Análisis comparativo de estudiante de grado 1003

Fuente: Fotografía tomada por autores.

Esta herramienta permitió abrir el panorama de los estudiantes y ofrecerles una visión global sobre los diferentes acontecimientos abordados. Un ejemplo de ello se puede vislumbrar al retomar los registros de los estudiantes en las tablas, en donde es claro que fueron capaces de identificar la relevancia e implicaciones de lo que significa un tratado de paz (un punto particularmente relevante dada la coyuntura de Colombia en torno al proceso y acuerdo de paz con la guerrilla de las FARC-EP). Lo anterior se concluyó a partir de la selección aleatoria de uno de los cursos, en este caso 1003, en el que se encontró que, de los 28 trabajos analizados, el $67,9 \%$ de estos identificaron que, frente a los conflictos armados en el mundo, la solución son los procesos de paz, junto con otros elementos como "tomar en cuenta la opinión del pueblo" o la "entrega de armas".

De igual forma, el registro en video realizado por el equipo docente permitió identificar la importancia del papel del profesor a cargo de las explicaciones, quien se caracterizó por adoptar un rol de mediador que facilitó la discusión grupal y el análisis integrado de cada caso. De esta manera, por medio de preguntas como ¿qué similitudes encuentran con respecto a los otros casos? o ¿en dónde más han escuchado que este tipo de situaciones se presenten? se fomentó el pensamiento crítico de los estudiantes para que construyeran, por sí mismos, los nexos entre cada caso abordado. Un claro ejemplo de ello se evidenció en el momento en el que uno de los docentes preguntó sobre al papel que jugó el problema de la tierra en cada conflicto y, acto seguido, los estudiantes comenzaron a participar identificando la presencia de este elemento en los diferentes contextos trabajados. Al final, fueron los mismos estudiantes quienes articularon esta variable, la tierra, a los cuatro casos abordados.

En paralelo, se debe resaltar el hecho de que el docente a cargo siempre buscó a lo largo del debate concientizar y resaltar la importancia de ciertos elementos como la solidaridad y empatía hacia otros individuos y grupos sociales. Esto se hizo por medio de anécdotas, hechos y evidencias que buscaron sensibilizar a los estudiantes y permitirles evidenciar otra cara del conflicto más allá de lo que comúnmente se conoce. Gracias a ello, se observó 
que gran parte del grupo pudo identificar en las causas de los conflictos elementos como la exclusión y el abuso de poder.

Tras haber abordado cada uno de los casos seleccionados, fue posible distinguir ciertos cambios en la percepción de los estudiantes. En un comienzo, ellos se mostraban indiferentes ante ciertas situaciones de injusticia y abuso de poder; sin embargo, para las discusiones finales, adoptaron posturas críticas que discutían los hechos presentados por los docentes. Un ejemplo de esto se evidenció al momento de retomar el conflicto colombiano cuando ya se habían trabajado temas de participación y democracia, pues al hablar sobre cómo se percibían las elecciones en un periodo de la historia de Colombia, un estudiante mostró su inconformismo y expresó: "ahí no se está teniendo en cuenta la democracia ¿cómo un voto de los conservadores va a valer tres votos liberales?" (Diario de campo 10-02, 2018). Esta intervención permitió establecer que los estudiantes cambiaron su postura, de indiferencia inicial, y adquirieron cierta capacidad para analizar y reconocer la importancia de la democracia y el papel de esta para convivir pacífica y constructivamente en una sociedad.

Frente a las preguntas de análisis propuestas para este módulo se pudo observar, por un lado, que los estudiantes lograron identificar las diversas causas y consecuencias de los conflictos armados en contextos diversos. Para este punto, fue claro que los estudiantes desarrollaron cierta capacidad para identificar qué elementos fueron los más influyentes en cada país, cuáles de estos están presentes en otro tipo de conflictos y de qué manera se puede encontrar una forma de solucionar o transformar de manera constructiva los conflictos. Por otro lado, al reconocer dichos aspectos se logró consolidar una visión crítica y generar cierta empatía y solidaridad con respecto a la situación por la que tuvieron que atravesar las personas involucradas en los diferentes conflictos. De igual manera, al identificar causas y establecer consecuencias, se pudo observar que los estudiantes identificaron aspectos claves como el diálogo bilateral, el reconocimiento de los derechos humanos y la participación ciudadana para estructurar posibles soluciones ante coyunturas específicas, como lo puede ser el posconflicto en Colombia.

\subsection{Movimientos sociales: El uso de portafolios pedagógicos}

Para la unidad de movimientos sociales se plantearon objetivos correspondientes a las dimensiones cognitiva, socioemocional y comportamental, los cuales que se convirtieron en preguntas para realizar el análisis de los resultados (cuadro 1). Con esta base, para comenzar, los estudiantes conformaron tríadas de trabajo cooperativo; posteriormente y durante la primera semana, se preguntaron acerca de cuáles eran los principales problemas que aquejaban a los grupos humanos marginados alrededor del mundo y quiénes se comprometían con luchar por reivindicar sus derechos. En este punto, partiendo de los saberes previos de los participantes, se estableció una lista de movimientos sociales que representaban acciones de la sociedad civil con impacto global, y de dicha lista, cada grupo se comprometió a asumir el rol de un movimiento social. Entre los movimientos sociales trabajados estuvieron: los movimientos obreros, LGTBI, afro, indígena, campesino, feminista, rastafari, hippie, okupa, vegano, ambientalista, estudiantil, de derechos humanos, insurgente, entre otros. A la par, se discutió en clase acerca de lo que representa el concepto de movimiento social y cuáles son sus distintas concepciones.

Luego de esta primera etapa, en la segunda semana cada uno de los grupos se dio a la tarea de mostrar mediante una imagen, cuáles eran los objetivos específicos en la lucha de cada movimiento social, de modo que las tríadas llevaron al aula los logos e íconos conocidos 
mundialmente y bajo los cuales se inscriben las reivindicaciones de cada movimiento. Tras esta socialización, la tercera semana se convirtió en un escenario musical, en el que cada grupo de trabajo dio a conocer el mensaje de su movimiento social y buscó comprometer y sensibilizar a sus compañeros mediante la presentación de videos musicales y el análisis de letras de canciones alusivas a las problemáticas, ideas, sentimientos, acontecimientos y demás cuestiones importantes para estos sectores.

Durante la cuarta semana, cada grupo tuvo el reto de buscar una película en la que se tratara algún tema relacionado con casos que afectaran a personas de sus movimientos sociales, o que fuesen un ejemplo notable en la lucha por los derechos de grupos marginados. Ello desembocó en un mini festival de cine en el que se presentaron trailers de obras cinematográficas bastante llamativas y profundas, que sirvieron de foco de discusión y reflexión. En la quinta semana, cada uno de los grupos realizó un escrito de análisis de lo aprendido y presentó un portafolio que recopiló todos los documentos socializados en las sesiones precedentes y que sintetizó la dinámica (figura 4).

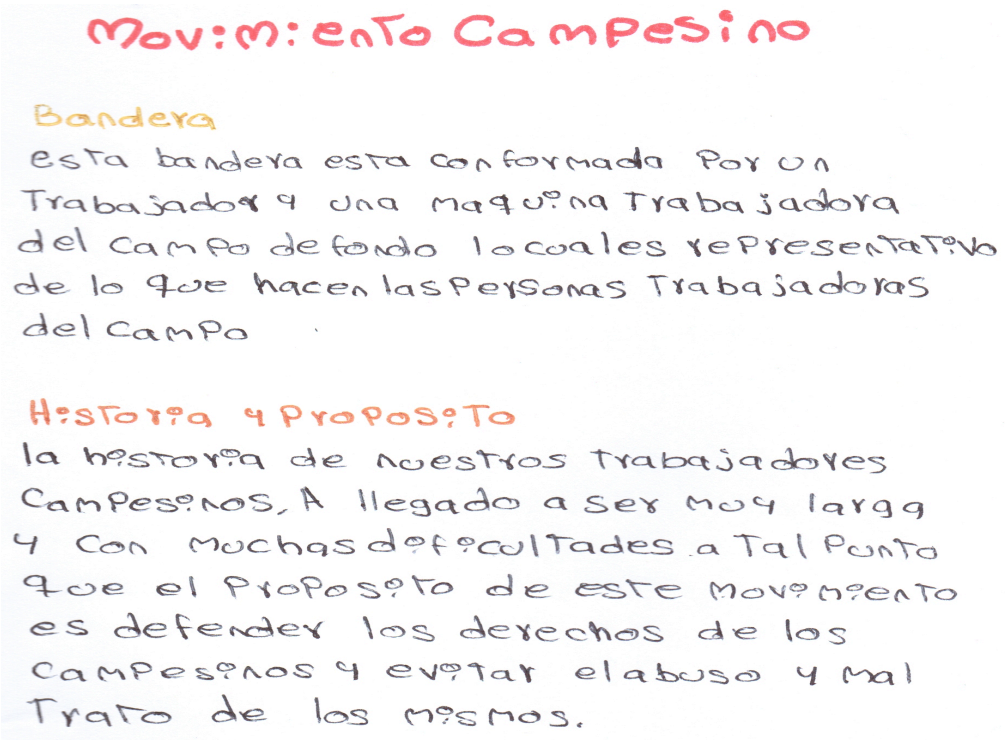

Figura 4. Ejemplo de una de las páginas de un portafolio Fuente: Fotografía tomada por autores.

Asimismo, como parte de la unidad de movimientos sociales tuvo lugar una actividad que se denominó Global Coffee Gourment. Esta actividad fue diseñada con la finalidad de que los estudiantes pudieran compartir los avances en la elaboración de sus portafolios con estudiantes de otro colegio oficial de Bogotá. La sesión tuvo lugar en las instalaciones de la Universidad de los Andes, lo cual propició un encuentro refrescante, significativo y distante de los espacios y aulas tradicionales. La intención de la actividad fue recrear una cena con tres momentos de reflexión sobre ciudadanía mundial, denominados Menú de Entrada, Plato Fuerte y Postre. Al iniciar la actividad se dividieron los estudiantes por grupos y se procuró que en cada grupo quedara conformado por estudiantes de ambos colegios. Cada grupo de estudiantes se ubicó en una mesa dispuesta para la cena, mientras que los profesores, de camisa y corbatín, pasaron mesa a mesa ofreciendo la carta.

El Menú de Entrada contenía una pregunta orientadora y tres opciones de bebida con importantes decisiones de vida para que discutieran en un tiempo aproximado de 20 
minutos: ¿Cuáles consideran que son los retos o dilemas de un joven ciudadano del mundo en la actualidad? a) Moka universitario: entrar o no a la universidad; b) Té inglés: aprender o no aprender una segunda lengua; c) Capuchino migrante: irse o no irse del país. Frente a tales preguntas, socializadas por un representante de cada grupo, se pudor notar la gran inquietud de los estudiantes por salir del país, con la idea de retornar para transferir conocimientos. También señalaron que el acceso a la educación superior aún es un privilegio en Colombia. Sin embargo, la opción más elegida fue el Té Ingles, pues consideran que aprender una segunda o tercera lengua es un aspecto fundamental para viajar, acceder a oportunidades laborales y complementar sus intenciones universitarias. Si bien en general hubo acuerdos, también se presentaron desacuerdos frente a algunos de los puntos. Por ejemplo, a propósito del "Capuchino migrante: Irse o no irse del país", uno de los grupos señaló:

Este tema es muy subjetivo ya que cada ser humano tiene una posición totalmente distinta. La postura colectiva que tenemos en la mesa es de un 50/50, los que están a favor tienen como objetivo el adquirir un mayor conocimiento de nuevas culturas y luego volver al país y poner en práctica lo aprendido. Aquellos que están en contra, tienen como posición el mantener nuestras raíces pues no debería haber un motivo por el cual irnos. (Estudiante de 17 años, 31 de julio de 2018)

El Menú de Plato Fuerte consistió en conocer el proceso que cada una de las instituciones educativas venía adelantando a lo largo del año sobre ciudadanía mundial. En el caso del colegio en el que se centra este artículo, los estudiantes socializaron sus portafolios, realizados en la clase de ciencias sociales. La pregunta orientadora fue la siguiente: ¿Al ser ciudadano del mundo qué haces para transformar el medio, localidad, barrio, colegio o mundo (comparte la experiencia desde tu colegio)? Esta actividad duró alrededor de una hora y permitió que los estudiantes expusieran su trabajo y aprendieran de las iniciativas realizadas por sus pares en otra institución educativa.

Para finalizar y, a manera de postre, se pidió a los estudiantes que eligieran cómo visibilizar, a través de las redes sociales digitales, una problemática que afectara actualmente a los ciudadanos del mundo. Para ello se propuso una actividad de cierre que permitiera a los estudiantes recorrer parte de la Universidad de los Andes y desplegar su creatividad a partir de las herramientas de sus teléfonos móviles. Entre las opciones de postre estaban las siguientes: Cheesecake de caricatura, Boomerang de chocolate, Meme de caramelo y Flan de teatro-imagen. Esta actividad fue de alto impacto y sus resultados se recopilaron en una página de Facebook diseñada previamente para ello: Ciudadanos del Mundo (disponible en: goo.gl/hCHMNP). En dicha página se puede acceder a las publicaciones derivadas de la actividad, las cuales se encuentran resumidas en el cuadro 3.

Como se puede observar, los estudiantes mostraron una fuerte sensibilidad frente a la desigualdad, y en menor medida frente a la discriminación, la contaminación, la violencia y la desinformación. Aunque el teatro-imagen fue seleccionado por algunos de los grupos, la mediación más recurrente fue el boomerang, herramienta de Instagram que permite grabar un video de corta duración ( 5 segundos) que se repite constantemente. Entre estos boomerangs, los que representaron situaciones de discriminación o desigualdad también fueron los que mayor impacto tuvieron, según el número de personas alcanzadas, el número de interacciones (reaccionar, comentar, compartir) y el número de reproducciones que obtuvieron. 
Cuadro 3. Resultado del ejercicio creativo del Global Coffee Gourment

\begin{tabular}{|c|c|c|c|}
\hline TEMA & POSTRE & TEXTO ASOCIADO A LA PUBLICACIÓN & IMPACTO \\
\hline Discriminación & $\begin{array}{l}\text { Boomerang } \\
\text { de } \\
\text { chocolate }\end{array}$ & $\begin{array}{l}\text { "Hemos aprendido a volar como pájaros, } \\
\text { a nadar como peces. } \\
\text { No hemos aprendido el sencillo arte de } \\
\text { vivir como hermanos" }\end{array}$ & $\begin{array}{l}237 \text { personas } \\
\text { alcanzadas } \\
23 \text { interacciones } \\
59 \text { reproducciones }\end{array}$ \\
\hline Discriminación & $\begin{array}{l}\text { Flan de } \\
\text { teatro } \\
\text { imagen }\end{array}$ & $\begin{array}{l}\text { "No a la violencia, no a la indiferencia: la } \\
\text { violencia no es la solución. } \\
\text { Dialoga y vive sin odio" }\end{array}$ & $\begin{array}{l}166 \text { personas } \\
\text { alcanzadas } \\
20 \text { interacciones }\end{array}$ \\
\hline Desigualdad & $\begin{array}{l}\text { Boomerang } \\
\text { de } \\
\text { chocolate }\end{array}$ & \#NoALaDesigualdad & $\begin{array}{l}180 \text { personas } \\
\text { alcanzadas } \\
23 \text { interacciones } \\
37 \text { reproducciones }\end{array}$ \\
\hline Desigualdad & $\begin{array}{l}\text { Boomerang } \\
\text { de } \\
\text { chocolate }\end{array}$ & $\begin{array}{l}\text { "Levantemos la voz por los que no } \\
\text { tienen voz" }\end{array}$ & $\begin{array}{l}232 \text { personas } \\
\text { alcanzadas } \\
25 \text { interacciones } \\
60 \text { reproducciones }\end{array}$ \\
\hline Desigualdad & $\begin{array}{l}\text { Boomerang } \\
\text { de } \\
\text { chocolate }\end{array}$ & $\begin{array}{l}\text { "En nuestra sociedad podemos } \\
\text { evidenciar grandes problemas como } \\
\text { son la desigualdad, discriminación, } \\
\text { violencia de género, y otras } \\
\text { problemáticas que afectan a nuestra } \\
\text { sociedad. } \\
\text { En este video podemos dar a conocer la } \\
\text { desigualdad mediante clases sociales, } \\
\text { género, cultura, y grupos sociales” }\end{array}$ & $\begin{array}{l}184 \text { personas } \\
\text { alcanzadas } \\
12 \text { interacciones } \\
31 \text { reproducciones }\end{array}$ \\
\hline Desigualdad & $\begin{array}{l}\text { Boomerang } \\
\text { de } \\
\text { chocolate }\end{array}$ & $\begin{array}{l}\text { ¿El dinero te hace superior a los demás? } \\
¡ N o \text { a la desigualdad económica!” }\end{array}$ & $\begin{array}{l}177 \text { personas } \\
\text { alcanzadas } \\
12 \text { interacciones } \\
55 \text { reproducciones }\end{array}$ \\
\hline Contaminación & $\begin{array}{l}\text { Boomerang } \\
\text { de } \\
\text { chocolate }\end{array}$ & $\begin{array}{l}\text { “Cuidar el planeta juntos es más } \\
\text { divertido” }\end{array}$ & $\begin{array}{l}199 \text { personas } \\
\text { alcanzadas } \\
26 \text { interacciones } \\
59 \\
\text { reproducciones. }\end{array}$ \\
\hline Violencia & $\begin{array}{l}\text { Boomerang } \\
\text { de } \\
\text { chocolate }\end{array}$ & $\begin{array}{l}\text { “En nuestro país y en general en el } \\
\text { MUNDO existe esta problemática que } \\
\text { tanto nos afecta. } \\
\text { Es necesario que todos entendamos que } \\
\text { el respeto mutuo es algo que debe } \\
\text { prevalecer y que nosotros, la } \\
\text { generación de cambio debemos } \\
\text { empezar a pensar en esto y } \\
\text { solucionarlo" }\end{array}$ & $\begin{array}{l}208 \text { personas } \\
\text { alcanzadas } \\
14 \text { interacciones } \\
52 \text { reproducciones }\end{array}$ \\
\hline
\end{tabular}

Fuente: Elaboración propia.

Ahora bien, el análisis de los portafolios se realizó a partir de las tres preguntas que orientaron la unidad. Frente a estas se evidenció, en primer lugar, que los estudiantes llegaron a defender las causas de los movimientos sociales y se manifestaron pacífica y creativamente para divulgarlas. Pese a no haber creado propiamente contenidos, seleccionaron temas musicales relativos a la lucha de los movimientos sociales y, por ejemplo, evidenciaron que la música es un vehículo de expresión, como lo comentó una estudiante:

En esta canción se dice que él quiere ser parte de un cambio, pero no está siendo escuchado... así que nosotros también podríamos forjar nuestra propia paz porque el país depende de nosotros y como jóvenes que estamos empezando a vivir, debemos 
luchar para que nos sintamos bien a pesar de todo, ya que si nosotros mejoramos Colombia va a mejorar. (Diario de campo 10-02, 2018)

En segundo término, los estudiantes examinaron críticamente los problemas locales, nacionales y mundiales frente a los cuales reaccionan los movimientos sociales, así como sus formas de acción colectiva. Aquí, los estudiantes revisaron características de las luchas de cada movimiento, sobre todo en términos de identificación de intereses sin importar el origen nacional, ya que las problemáticas abordadas por el feminismo, por ejemplo, atañen a muchas mujeres a nivel mundial. Lo anterior fue tratado en una de las clases y quedó registrado en uno de los diarios de campo:

El docente pregunta si este tema solo afecta a las mujeres colombianas y una estudiante responde: "me gustó la frase que dice 'no me digas qué hacer y no me exhibas'. Esto da a entender que la mujer no es un objeto. Aunque los medios de comunicación implanten cánones de belleza que cambian según cada país, de todas maneras, nos han inculcado a todas cómo tiene que ser nuestro cuerpo para no parecer feas. (Diario de campo 10-01, 2018)

En tercer lugar, se identificaron y comprometieron empáticamente con la reivindicación de grupos marginados. Por ejemplo, en la sesión de análisis de imágenes asociadas al movimiento LGTBI, una estudiante comentó: “ipor qué una pareja heterosexual sí puede hacerlo y una pareja homosexual no? Eso es doble moral” (Diario de campo 10-01, 2018). Asimismo, resultó significativo ver cómo mediante el análisis de la canción Hasta siempre, comandante, dedicada a Ernesto Guevara, un estudiante señaló:

Me gustó ver cómo el Che luchaba por los más necesitados, a él no le importaba sacrificar su vida, de hecho, yo investigué algunas frases que me emocionaron, por ejemplo, que hay que vivir como si ya estuviéramos muertos y que debemos ser la pesadilla de los que quieren quitarnos los sueños. (Diario de campo 10-02, 2018)

Por estas razones, consideramos que esta unidad en particular ha aportado de manera considerable a la formación de los participantes como ciudadanos del mundo. En palabras de una de las tríadas:

Ser un ciudadano del mundo significa en la totalidad de la palabra, no solo pensar en el hecho que naciste en un país y solo por esto eres solo ciudadano de este; es pensar en que el mundo está para ser visitado, valorado y conocido. Esto implica mantener la mente abierta (...) ser un ciudadano del mundo significa estar dispuesto a conocer cada problema y a intentar buscarle una solución (...) pudimos aprender valores tales como el respeto, la justicia, la libertad para ser quien se es y defender lo que se piensa. (Portafolio 10-01, 2018)

Del mismo modo, otro de los grupos resaltó:

Es importante participar en la vida social, política y económica de la sociedad. Como ciudadanos el compromiso está en informarnos tanto en nuestro país como en todo el mundo para aportar con opiniones e ideas valiosas que ayuden a mejorar, con la convicción de ser libres y sin temor de ser rechazados. (Portafolio 10-03, 2018)

\section{Discusión y conclusiones}

La ECM no puede pensarse al margen del acelerado y complejo fenómeno de la globalización que produce continuos cambios en la esfera económica, política y cultural, y somete a las personas a nuevos riesgos de dimensiones globales: depredación ambiental, violencias, desigualdad social, discriminación, vulneraciones de los derechos humanos, entre otros. Como afirma Boni (2011) si bien no es la primera vez que la humanidad padece conflictos y sufrimientos, sí resulta novedoso que en las últimas décadas el ser humano se 
haya vuelto un poco más consciente de que esta es la realidad global. Sin embargo, aunque exista cierta conciencia acerca de la situación adversa del planeta, aún es necesario emprender experiencias concretas de educación para la ciudadanía y de ECM que respondan a esta toma de conciencia y contribuyan a la construcción de un mundo más justo, pacífico y ambientalmente responsable.

Lo anterior es especialmente relevante en sociedades en "posconflicto" como la colombiana. Como explican Reilly y Niens (2014) en su análisis del caso de Irlanda del Norte, un país en posconflicto que aún mantiene una sociedad dividida y un sistema educativo segregacionista, la ECM resulta estratégica en este tipo de sociedades y puede devenir en un medio fundamental para sobrepasar las fracturas, violencias y heridas que dividen a sectores antagónicos de la sociedad. Esto gracias a que, más allá de la "tolerancia frente a la diferencia”, la ECM favorece la comprensión profunda de los significados socialmente construidos y atribuidos a los actores sociales, así como el entendimiento de los sentidos culturales o motivaciones políticas que explican buena parte de las tensiones y conflictos sociales locales. En la misma línea, Han (2016) destaca la manera como la ECM, dada su apuesta por acoger la diversidad cultural, puede ser un medio para construir el entendimiento entre las dos Coreas y avanzar hacia la unificación, teniendo en cuenta que, pese a vivir bajo normas sociales distintas, ambas Coreas comparten historia, lengua y valores culturales que consolidan soportes necesarios para la comprensión mutua y la convivencia pacífica.

En el caso colombiano, del mismo modo, la ECM puede contribuir a la negociación pacífica de las tensiones entre sectores históricamente antagónicos que, con la firma del acuerdo de paz en 2016, iniciaron una nueva etapa de disputa y negociación, pero ahora en la arena política y por medio de la participación democrática. En paralelo, las heridas, odios heredados y violencias enquistadas en una sociedad que naturalizó durante décadas la discriminación, negación y eliminación del otro, pueden lentamente transformarse en iniciativas de paz y construcción de justicia social, a través de procesos de ECM. Para ello, la puesta en marcha de estrategias educativas como las descritas en el presente artículo permite dar un paso adelante. La investigación-acción expuesta, centrada en la práctica de un docente de ciencias sociales de un colegio oficial de Bogotá, evidenció varias potencialidades de las experiencias pedagógicas propuestas, orientadas a la formación de competencias para la ciudadanía mundial en jóvenes de entre 14 y 17 años.

En primer lugar, se identificó que a través de estrategias lúdicas e innovadoras como el teatro-imagen, los estudiantes comprenden las diferencias entre distintos sistemas de gobierno y, en especial, las características, posibilidades y tensiones de la participación democrática. Asimismo, por medio de ejercicios comparativos, los estudiantes logran expandir su mirada y comprender la complejidad del conflicto armado en Colombia, al analizarlo en diálogo con los antecedentes, causas, hechos, consecuencias y procesos de transición democrática acontecidos en otros países (Ruanda, El Salvador e Irlanda del Norte). Del mismo modo, gracias al trabajo grupal, a la investigación y al intercambio materializado en una mediación pedagógica como el portafolio, los estudiantes comprenden las motivaciones y formas de acción de los movimientos sociales globales, se identifican empáticamente con la defensa de los derechos humanos y se manifiestan pacífica y creativamente en contra de la desigualdad, la discriminación, la contaminación, la desinformación y las violencias en el mundo. 
Estos logros fueron posibles, entre otros, gracias a la autonomía que la Ley General de Educación en Colombia provee a sus docentes para empoderarse de sus currículos, transformarlos de maneras innovadoras y, así, responder a las necesidades de sus contextos locales y a los desafíos de las problemáticas mundiales. Lo anterior, sumado a un trabajo colaborativo de un equipo de investigación heterogéneo, no solo permitió enriquecer el currículo y la práctica pedagógica de un docente, sino también potenció los aprendizajes de estudiantes de media, que se nutrieron de una mirada crítica de los problemas de su nación, en articulación con otras experiencias históricas en el mundo.

Si bien el centro del análisis de este estudio estuvo en la observación del aprendizaje de los estudiantes, es ineludible hablar de la relevancia que tuvo el proceso de investigación en la práctica del docente, así como el rol protagónico que este cumplió en el éxito de la intervención. El docente de ciencias sociales era un licenciado en ciencias sociales con más de ocho años de experiencia como docente y con un alto grado de compromiso con la formación de sus estudiantes y con su propia formación. Al momento de realizar el estudio, acabada de finalizar un programa de maestría en educación, a partir del cual se conectó con algunas de las personas del equipo de investigación para continuar de manera autónoma con su formación como docente investigador. Estas particularidades del docente, sumadas al trabajo colaborativo del equipo de investigación, sin duda tuvieron un peso importante en el éxito de las estrategias implementadas. Pero, más aún, se vieron reflejadas en las transformaciones de la práctica del docente, ya que una de las estrategias desarrolladas, la de portafolios pedagógicos, fue propuesta, implementada y evaluada de manera más bien independiente por parte del docente. De allí que valga la pena resaltar el importante papel que cumplen tanto la motivación del maestro para transformar su práctica, como el trabajo colaborativo que pueda establecer con otros colegas para enriquecerla.

Con respecto a los estudiantes se puede afirmar, además, que las tres experiencias pedagógicas propuestas les permitieron ir más allá de una comprensión puramente cognitiva de los "problemas mundiales" y transitar hacia una transformación emocional y actitudinal. Sin embargo, el trabajo dejó el reto de profundizar más en el desarrollo de la dimensión comportamental de las competencias para la ciudadanía mundial, pues la evaluación de los efectos de las tres experiencias evidenció menores cambios en esta dimensión, en comparación con los ámbitos cognitivo y socioemocional. Lo anterior no obedece a un error metodológico o a no haber tenido la intención de generar aprendizajes en este nivel, sino a elementos más estructurales.

Por ejemplo, Colombia no es un país que cuente con una trayectoria fuerte de movilización de estudiantes de secundaria, a diferencia de otros contextos latinoamericanos (Aguilera, 2006; Aguilera 2011; Valderrama, 2013). Con excepción de ciertas oleadas de acción colectiva en la que los estudiantes de secundaria se han sumado a las demandas de los estudiantes universitarios en defensa de una educación pública y de calidad, como sucedió especialmente en 2011 (Sánchez, 2012) y en el paro nacional de 2019, la vivencia de la participación ciudadana de estos estudiantes se ha ligado mucho más a los mecanismos formales de participación de sus colegios (como la elección de representantes estudiantiles) y no tanto a este otro tipo de dinámicas de participación política directa que evidencian competencias comportamentales de ciudadanía mundial.

Ello implica que, para próximas experiencias, es necesario enfatizar especialmente en aquellas habilidades que conectan con comportamientos y prácticas específicas que 
aportan, desde el activismo social, a la ciudadanía mundial, como la apropiación crítica de tecnologías digitales, la difusión de campañas globales, la firma de peticiones virtuales para generar presión sobre problemas mundiales, entre otras dinámicas de ciberactivismo y ciudadanía mundial que han sido documentadas en otros estudios (Aguilar-Forero, 2019; Truong-White y Mclean, 2015). La preferencia de los jóvenes por redes sociales como Instagram y el alto impacto que tuvieron sus publicaciones como parte de este estudio (en especial los boomerangs para generar conciencia sobre problemáticas mundiales), ofrecen pistas relevantes de hacia dónde orientar futuras estrategias.

Asimismo, este estudio arroja unas lecciones aprendidas que pueden ser replicadas en otros contextos. En particular, queremos resaltar que, para desarrollar procesos de integración curricular de las competencias para la ciudadanía mundial en las áreas académicas, es fundamental preguntarse por la relevancia de los objetivos de aprendizaje en función de los desafíos mundiales, así como diseñar e implementar experiencias de aprendizaje que promuevan el pensamiento crítico y la discusión abierta y profunda de temas controversiales. Esto fue posible en el caso expuesto gracias a mediaciones pedagógicas como el teatro-imagen, las fichas comparativas y el uso de portafolios, en los que encontramos potencialidades para promover la ECM dado su carácter lúdico y participativo. Estas mediaciones favorecen experiencias que empoderan al estudiante en su proceso de aprendizaje y que, en concordancia con los objetivos de la ECM, promueven la formación de ciudadanos participativos, activos, críticos y reflexivos.

El trabajo de Rapoport (2013), basado en entrevistas semiestructuradas y 40 sesiones de observación de aula en clases de ciencias sociales de escuelas de Estados Unidos, llega a resultados que dialogan con los expuestos en el presente estudio. Por ejemplo, encuentra que la dramatización, el juego de roles, la formulación de retos o desafíos y, en especial, los debates sobre temas controversiales y la comparación (diacrónica y sincrónica), son las metodologías más utilizadas por los docentes de ciencias sociales. Se destaca en especial la comparación, en tanto permite alcanzar dos objetivos complementarios: contrastar hechos, datos y fenómenos que evidencian diferencias entre países (como prueba de que el mundo es culturalmente diverso), y demostrar lo mucho que tienen en común las sociedades, gentes y países, a pesar de sus diferencias.

En concordancia con lo anterior, el presente estudio utilizó la aproximación comparativa en una de sus estrategias (unidad sobre conflicto armado), pero integró además otras mediaciones pedagógicas aún poco utilizadas para promover la ECM, como el teatroimagen y el portafolio, los cuales permitieron generar comprensiones desde dinámicas colectivas y divertidas para los estudiantes. Adicionalmente, esta investigación-acción aportó una estrategia innovadora para evaluar los aprendizajes de los estudiantes, relativos a la ciudadanía mundial: el mapeo de conocimientos y significados. Si la tendencia para desarrollar competencias de ciudadanía mundial se orienta hacia estrategias metodológicas no convencionales que superan las prácticas pedagógicas transmisionistas y favorecen la innovación educativa, las formas de evaluar no se pueden quedar atrás. Es necesario promover prácticas evaluativas innovadoras y coherentes con este tipo de estrategias en las que los estudiantes y no solo el docente, ocupan un rol fundamental.

Para terminar, cabe enfatizar que esta innovación curricular en la que se lograron modificar los contenidos, las estrategias pedagógicas y el sistema de evaluación, solo es posible con el liderazgo de un docente autónomo y creativo como el que participó en el presente estudio. También requiere de instituciones educativas que, como aquella en la 
que se trabajó, cuentan con directivos con una visión abierta y favorable a la innovación. No obstante, expandir este tipo de experiencias y lograr que desborden el trabajo de aula no es una tarea fácil. Se requiere de acompañamiento y orientación en los procesos de diseño curricular por parte de las instituciones de gobierno (secretarías de educación locales y ministerios de educación nacionales), más allá de las buenas intenciones de los grupos de investigación universitarios cuyo alcance y recursos son reducidos. Se requieren, además, procesos de formación a los futuros docentes y a los docentes en ejercicio para que reconozcan, como señala Rapoport (2013), la importancia de la ECM y no la desplacen a un lugar secundario frente a lo que se considera como "verdaderamente necesario".

\section{Referencias}

Aguilar-Forero, N. (2019). Ciberactivismo y educación para la ciudadanía mundial: Una investigación-acción participativa con dos experiencias educativas de Bogotá. Palabra Clave, 22(2), 1-31. https://doi.org/10.5294/pacla.2019.22.2.10

Aguilar-Forero, N. y Velásquez, A. M. (2018). Educación para la ciudadanía mundial en Colombia: Oportunidades y desafíos. Revista Mexicana de Investigación Educativa, 23(78), 937-961.

Aguilera, O. (2006). Movidas, movilizaciones y movimientos. Etnografía al movimiento estudiantil secundario en la quinta región. Revista Observatorio de Juventud, 11, 34-42.

Aguilera, O. (2011) Acontecimiento y acción colectiva juvenil. El antes, durante y después de la rebelión de los estudiantes chilenos en el 2006. Propuesta Educativa Número 35(1), 11-26

Aktas, F., Pitt, K., Richards, J. C. y Silova, I. (2017). Institutionalizing global citizenship: A critical analysis of higher education programs and curricula. Journal of Studies in International Education, 21(1), 65-80. https://doi.org/10.1177/1028315316669815

Andreotti, V. (2011). (Towards) decoloniality and diversality in global citizenship education. Globalisation, Societies and Education, 9(4), 381-397. https://doi.org/10.1080/14767724.2011.605323

Andreotti, V. y Pashby, K. (2013). Digital democracy and global citizenship education: Mutually compatible or mutually complicit? The Educational Forum, 77(4), 422-437. https://doi.org/10.1080/00131725.2013.822043

Arthur, J. (2014). The longings and limits of global citizenship education: The moral pedagogy of schooling in a cosmopolitan age. By Jeffrey S. Dil. British Journal of Educational Studies, 62(1), 73-74. https://doi.org/10.1080/00071005.2013.877621

Balarin, M. (2011). Global citizenship and marginalisation: Contributions towards a political economy of global citizenship. Globalisation, Societies and Education, 9(4), 355-366. https://doi.org/10.1080/14767724.2011.605321

Boni, A (2011). Educación para la ciudadanía global. Significados y espacios para un cosmopolitismo transformador. Revista Española de Educación Comparada, 17, 65-86.

Boni, A., Hofmann-Pinilla, A. y Sow, J. (2012). Educando para la ciudadanía global. Una experiencia de investigación cooperativa entre docentes y profesionales de las ONGD. Estudios Sobre Educación, 23, 63-81.

Cho, H. S. y Mosselson, J. (2017). Neoliberal practices amidst social justice orientations: Global citizenship education in South Korea. Compare: A Journal of Comparative and International Education, 47(4), 1-18. 
Falk, J. (2003). Personal meaning mapping. En G. Caban, C. Scott, y J. Falk (Eds.), Museums and creativity: A study into de role of museums in design education (pp. 10-18). Sydney: Powerhouse Publishing.

Han, Y. H. (2016). Challenges and tasks of global citizenship education in East Asia: assimilation policy of multicultural family students in South Korea. Revista Española de Educación Comparada, 28, 53-71. https://doi.org/10.5944/reec.28.2016.17088

Hartung, C. (2017). Global citizenship incorporated: Competing responsibilities in the education of global citizens. Discourse: Studies in the Cultural Politics of Education, 38(1), 16-29. https://doi.org/10.1080/01596306.2015.1104849

Jaramillo, R. y Mesa, J. (2009). Citizenship education as a response to Colombia's social and political context. Journal of Moral Education, 38(4), 467-487.

https://doi.org/10.1080/03057240903321931

Jooste, N. y Heleta, S. (2017). Global citizenship versus globally competent graduates: A critical view from the South. Journal of Studies in International Education, 21(1), 39-51. https://doi.org/10.1177/1028315316637341

Latorre, A. (2007). La investigación-acción. Conocer y cambiar la práctica educativa. Barcelona: Graó.

MEN. (2004). Estándares básicos de competencias ciudadanas. Bogotá: Ministerio de Educación Nacional.

MEN. (2006). Estándares básicos de competencias en lenguaje, matemáticas, ciencias y ciudadanas. Bogotá: Ministerio de Educación Nacional.

MEN. (2018). Lineamientos de formación de educadores para la ciudadanía. Bogotá: Ministerio de Educación Nacional.

Nieto, D. (2017). Citizenship education discourses in Latin America: Multilateral institutions and the decolonial challenge. Compare: A Journal of Comparative and International Education, 48(3), 1-17. https://doi.org/10.1080/03057925.2017.1408399

ONU. (s.f.). Objetivo 4: Garantizar una educación inclusiva, equitativa y de calidad y promover oportunidades de aprendizaje durante toda la vida para todos. Recuperado de https://www.un.org/sustainabledevelopment/es/education/

Pais, A. y Costa, M. (2017). An ideology critique of global citizenship education. Critical Studies in Education, 58(1), 1-16. https://doi.org/10.1080/17508487.2017.1318772

Parmenter, L. (2011). Power and place in the discourse of global citizenship education. Globalisation, Societies and Education, 9(4), 367-380.

https://doi.org/10.1080/14767724.2011.605322

Peraza, C. (2016). Interpretaciones de la educación para la ciudadanía global en la reforma de la educación media superior en México. Revista Española de Educación Comparada, 28, 135-159. https://doi.org/10.5944/reec.28.2016.17092

Rapoport, A. (2013). Global citizenship themes in the social studies classroom: Teaching devices and teachers' attitudes. The Educational Forum, 77, 407-420.

https://doi.org/10.1080/00131725.2013.822041

Reilly, J. y Niens, U. (2014). Global citizenship as education for peacebuilding in a divided society: Structural and contextual constraints on the development of critical dialogic discourse in schools. Compare: A Journal of Comparative and International Education, 44(1), 53-76. https://doi.org/10.1080/03057925.2013.859894

Plan de Área. (2015). Presentación general del plan de área: áreas: ciencias sociales, ciencias económicas y políticas, filosofía, religión y ética y valores. Documento sin publicar. 
Shultz, L. (2007). Educating for global citizenship: Conflicting agendas and understandings. Alberta Journal of Educational Research, 53(3), 248-258.

Sánchez, D. (2012). ¿Cómo ha sido la vuelta? Breves notas sobre la organización y el movimiento juvenil colombiano. En E. Rodríguez (Ed.), Movimientos juveniles en América Latina y el Caribe: entre la tradición y la innovación (pp. 47-68). Lima: CELAJU.

Standish, A. (2014). What is global education and where is it taking us? The Curriculum Journal, 25(2), 166-186. https://doi.org/10.1080/09585176.2013.870081

Truong-White, H., y Mclean, L. (2015). Digital storytelling for transformative global citizenship education. Canadian Journal of Education, 38(2), 1-29. https://doi.org/10.2307/canajeducrevucan.38.2.11

Valderrama, L. B. (2013). Jóvenes, ciudadanía y tecnologías de información y comunicación. El movimiento estudiantil chileno. Revista Latinoamericana de Ciencias Sociales, Niñez y Juventud, $11(1), 123-135$.

Veugelers, W. (2011). The moral and the political in global citizenship: Appreciating differences in education. Globalisation, Societies and Education, 9(4), 473-485.

https://doi.org/10.1080/14767724.2011.605329

UNESCO. (2015). Global citizenship education: Topics and learning objectives. París: UNESCO.

UNESCO. (2018). Global citizenship education: Taking it local. París: UNESCO.

\section{Breve CV de los autores}

\section{Nicolás Aguilar-Forero}

Investigador posdoctoral de la Facultad de Educación de la Universidad de los Andes (2017-2018). Doctor en Ciencias Sociales, Niñez y Juventud del Centro de Estudios Avanzados en Niñez y Juventud (Universidad de Manizales-Cinde). Magíster en Estudios Culturales de la Pontificia Universidad Javeriana de Bogotá. Antropólogo y Profesional en Lenguajes y Estudios Socioculturales de la Universidad de los Andes. Sus áreas de interés abordan temas relacionados con la acción política juvenil, la construcción de memoria histórica, la educación para la ciudadanía mundial y los vínculos entre tecnologías digitales y educación. ORCID ID: https://orcid.org/0000-0002-9181-0281. Email: nj.aguilar1902@uniandes.edu.co

\section{Diego Fernando Mendoza Torres}

Magíster en Educación de la Universidad de los Andes. Licenciado en Ciencias Sociales de la Universidad Distrital Francisco José de Caldas. Docente de la Secretaria de Educación de Bogotá y asistente de investigación de la Facultad de Educación de la Universidad de los Andes de Bogotá, Colombia. Sus áreas de interés abordan temas relacionados con la enseñanza aprendizaje de las Ciencias Sociales, la educación para la ciudadanía mundial y la formación docente. ORCID ID: https://orcid.org/0000-00033466-4457. Email: df.mendoza@uniandes.edu.co

\section{Ana María Velásquez}

Doctora en Psicología, Concordia University. Magíster en Educación de la Universidad de los Andes. Psicóloga de la universidad de los Andes. Profesora asociada de la Facultad de Educación de la Universidad de los Andes de Bogotá, Colombia. Sus áreas de interés 
abordan temas relacionados con la formación ciudadana, la educación para la ciudadanía mundial, el desarrollo socioemocional y el clima de aula. ORCID ID:

https://orcid.org/oooo-0002-6868-6198. Email: ana-vela@uniandes.edu.co

\section{Daniel Felipe Espitia}

Estudiante de la Facultad de Educación y Ciencia Política de la Universidad de los Andes de Bogotá, Colombia. Sus áreas de interés abordan temas relacionados con el trabajo y desarrollo comunitario especialmente en torno a la educación, diseños institucionales a nivel del aula y el manejo de esta. ORCID ID: https://orcid.org/0000-0001-8168-4878. Email:df.espitia@uniandes.edu.co

\section{Jennifer Ducón Pardey}

Aspirante a Master de la Universidad Internacional de la Rioja en Intervención Social y sociedades del conocimiento. Actualmente está vinculada a la Secretaria de Educación de Bogotá como docente en el proyecto de Educación Media Integral en el área de gestión de proyectos. Sus áreas de interés abordan temas relacionados con ABP o PBL (Projectbased learning) y la incidencia de las tecnologías en la participación local juvenil. ORCID ID: https://orcid.org/o000-0002-4261-1729. Email: jnduconp@educacionbogota.edu.co

\section{Jana De Poorter}

Actualmente cursa un programa de calificación docente en la Universidad de Leiden (Países Bajos). Tiene una Maestría en Investigación en Estudios de Desarrollo Internacional de la Universidad de Ámsterdam y una licenciatura en Estudios Internacionales de la Universidad de Leiden. A partir de un trabajo de campo que realizó en Costa Rica y Colombia, sus intereses investigativos se han centrado en la educación para la ciudadanía mundial en América Latina. ID ORCID: http://orcid.org/0000-00016610-0176. Correo electrónico depoorter.jana@gmail.com 